\title{
The psychological safety of students in the context of digitalization as a factor of social health
}

\author{
Anastasia Bashkireva ${ }^{1, *}$, Tatyana Bashkireva ${ }^{1}$, Alexander Morozov ${ }^{2}$, Anastasia \\ Evdokimova $^{3}$, and Sergey Tsvetkov ${ }^{4}$ \\ ${ }^{1}$ Ryazan State University named after S.A. Yesenin, 390000 Ryazan, Russia \\ ${ }^{2}$ Research Center, The Federal State Institution "Research Institute of the of the Federal penitentiary \\ service of Russia", 125130 Moscow, Russia \\ ${ }^{3}$ Saratov State Medical University named after V.I. Razumovsky, 410012 Saratov, Russia \\ ${ }^{4}$ Vladimir branch of the Russian presidential Academy of national economy and public \\ administration, 600017 Vladimir, Russia
}

\begin{abstract}
The article provides a rationale for the need to study psychological safety as a factor of social health of the intensive development of digitalization. Students, teachers, parents of various social groups become hostages of colossal information, which is contradictory and affects the social norms of the culture of specific peoples. Education is becoming more inclusive. Social cognitive dissonance arises, negatively affecting the social health of participants in education. The paper presents a model of the concept of psychological safety of students, which includes the following components: 1) safe digital content, taking into account age characteristics and ethnic and confessional values; 2) preservation and strengthening of social health; 3) self-development of personal and professional qualities of participants in education, taking into account the cognitive needs and analysis of the digital footprint.
\end{abstract}

\section{Introduction}

It is not possible to achieve sustainable development solely through technology, political regulation or financial mechanisms. Humanity needs to change the way we think and behave. In turn, it requires the provision of quality education and training for sustainable development at all levels and regardless of social conditions. [2].

The up-to-date rates of scientific and technological development of society are dynamically changing the spheres of social life. The COVID-19 pandemic made it clear that irreversible overstrain processes in socio-economic development took place in our world [3; $30]$. We are entering a new era. No matter how much we argue about the nature of the appearance of the disease, its danger to the lives of children and adults is obvious [15; 24]. The rapid spread and high mortality began to seriously threaten the physical and mental,

\footnotetext{
* Corresponding author: bashkireva32@gmail.com
} 
social health of people $[27 ; 29]$. Many countries forced to introduce a lockdown and transfer institutions to work remotely, including educational organizations [3; 30]. This situation has intensively stimulated the introduction of digitalization in the areas of social life [2].

Some researchers suggest that electronic and virtual education will be effective when using forms of innovative communication between participants in the educational process. [19]. The development of digital competencies will ensure high-quality education; provide that the health of the participants in the educational process be taken care of $[3 ; 25]$. Such learning allows one to transcend geographic and temporal space and create an accessible environment for acquiring holistic knowledge in various fields of activity [4].

However, the intensive introduction of digitalization into education has negative psychological characteristics. For example, students receive a variety of information that contains factual errors; cognitive dissonance about social values is forming; self-esteem becomes dependent on cyber fashion; interpersonal trust is violated $[14 ; 16 ; 18]$.

On the part of society, there is a need to create a safe psychological environment for a person, especially the younger generation, as a significant factor in social health. Psychological safety provides basic human needs $[1 ; 20]$.

Some researchers consider psychological safety in a medical aspect $[10-13 ; 33]$. And this is advisable. People are sensitive to the opinions of others, and this affects their mental state. There is a high likelihood of cyber addiction $[7-8 ; 26 ; 28 ; 31]$.

In this regard, we can consider psychological safety as a psychological climate in which group conflict decreases due to the distancing of participants in the educational process [6; 22].

Climate proponents argue that people respond primarily to cognitive beliefs about their environment, not to the interpersonal relationships in the environment where they learn [17]. However, perceptions can differ based on personal and individual beliefs.

Modern trends in the development and implementation of artificial intelligence in education have necessitated the creation of psychological safety for participants in the educational process as a factor of social health [4; 23-24].

Social health was not sufficiently researching and study in psychology. A significant condition for social health is its quality, which is usually associated with a healthy lifestyle. The quality of the population's health reflects the viability of society, the possibility of its continuous harmonious growth and socio-economic development [32].

In literary sources, social health most often characterized as an adequate perception of social reality and the surrounding world. Adaptation to the physical and social environment, orientation towards socially wholesome business, a culture of consumption, altruism, empathy, responsibility towards others, selflessness, democratism in behaviour $[5 ; 21]$. We believe that the problem of social (public) health, especially of children and youth, deserves the closest attention. Heterochronous and heterogeneously developing children's organism requires a careful attitude to itself $[12 ; 24]$.

We believe that the concept of social health well-being divides into the social health of a specific person and the social health of the population.

From our mind, the social health of the human is a reflection of a combination of the physiological, mental, psychological, cultural and economic state of society. Social health is a reflection by gender-age groups of biological, psychological, cultural-historical, demographic, socio-value characteristics and conditions of public in specific climatic, ecological, socio-historical, cultural and ethnic conditions [3].

Psychological safety as a factor of social health is becoming necessary due to global digitalization.

The aim is to develop a model of human psychological safety in the conditions of digitalization as a factor of social health using the example of educational organizations. 


\section{Method}

The use of meta-analysis made it possible to understand that the intensive development and introduction of informatization in education can lead to cyber education, the loss of socially significant ethnic and confessional values. Therefore, not to lose the historical values accumulated by each state, the younger generation accompanied by the labyrinth of cyber information.

During the lockdown period, there was a demand for distance learning. A survey of students $(n=351$ people $)$ conducted on the importance of digital education. Within a month, the students underwent health diagnostics remotely. The indicators of the cardiovascular system studied using the Belgian test "Reaction of the cardiovascular system to load in the form of torso bending".

\section{Results and discussion}

The urgency of the problem of social health lies in the comprehensive study of the psychological safety of a person. When we speak about digitalization, we see the problem with the intercultural communication of students. Due to individual and cultural differences, a person is a bearer of social values. From birth, he learns the significance of the society in which he grows and develops on the territory of a particular state with its centuries-old cultural history. At the same time, a person sees contradictions in the values of this society. Because of cognitive dissonance, a person develops ideas about the values around him.

The preservation of the health of the human population and each person is the most significant aspect of scientific research since we are talking about the care of the biological species "man". The intensive development of information and communication means to trace its mark. The question arises that psychological safety must include among the factors of social health of the human population.

Internet information, with a variety of different content about the socio-cultural, moral and moral values of civil society in social networks, more often unfavorable for students (whose opinions and beliefs are at the stage of formation and development), destroys evolutionarily established values and becomes a threat to the assimilation of value orientations of the growing up generations. The content and results of diverse intercultural contacts depend on the organization of its participants' readiness to reach an agreement.

In connection with globalization, education has become available in any country in the world. Young people actively migrate and join the new cultural environment. Impressions about a different culture emotionally coloured by feelings: surprise, anxiety, anxiety, sometimes aggression towards other social values. The digitalization of education is also causing symptoms of culture shock. Under the influence of intensively developing artificial intelligence technologies, psychological acculturation is gaining relevance. Human psychology, his role behaviour, attitudes, mental state, lifestyle and quality of life constantly changing as conditions of social health.

The intensive development of scientific and technological progress, the methods that teachers traditionally use in teaching do not allow them to implement the transference of knowledge to students. During the pandemic, many distance-learning educators have successfully used virtual learning and communication infrastructure [30].

We currently live in a world where Internet access is a basic need. In this period, an important task of education is the creation, development and maintenance of means for virtual and telematic interaction [30]. The growth of networks and virtual settings, coupled with video conferencing, has ensured the continuity of the educational space in which students and educators meet and work with conventional learning resources. A different communication environment has appeared - cyber communication. 
How does digitalization affect the health of students? During the 30-day distance-learning period, we studied the student's health in terms of the cardiovascular system using the Belgian test "Reaction of the cardiovascular system to load in the form of torso bends."

The average level of health found in $78.6 \%$ overstrain the functional state in $21.4 \%$ of the students. We attributed this group to the risk group, regardless of the number of hours they spent at the computer.

We also studied the opinion of students $(n=351$ people) about the importance of digital education:

- $87 \%$ supported the introduction of digital technologies in the educational process;

- $63 \%$ have adapted to the conditions of the introduction of informatization without difficulty; - $72 \%$ emphasized that the advantage of digital learning lies in the flexibility of the educational process;

- $43 \%$ believe that the quality of education will improve with the use of digitalization;

- 52\% expressed confidence in the effectiveness of digital education under the guidance of a teacher;

- 56\% indicated that digital education develops skills for self-development and self-control.

However, $90 \%$ of students preferred traditional education.

It is an interesting question about devices students use to find digital information to prepare them for classes. It was revealed that $38 \%$ use a stationary computer, $46 \%$ - a laptop, $4 \%$ - a tablet; $12 \%$ - with a mobile phone.

A survey of students' opinions showed that using digital technologies increased the motivation to acquire knowledge by $27 \%$, decreased by $35 \%$, and did not change in $38 \%$. A positive effect of the quality of information using digital technologies noted by $15 \%$ of student's negative $-50 \%$, did not change $-35 \%$.

Everyone understands that the introduction of digital technologies and artificial intelligence will inevitably come to education. Based on the above, we have developed a working model of the structure of the psychological safety of students in the context of digitalization (Fig. 1).

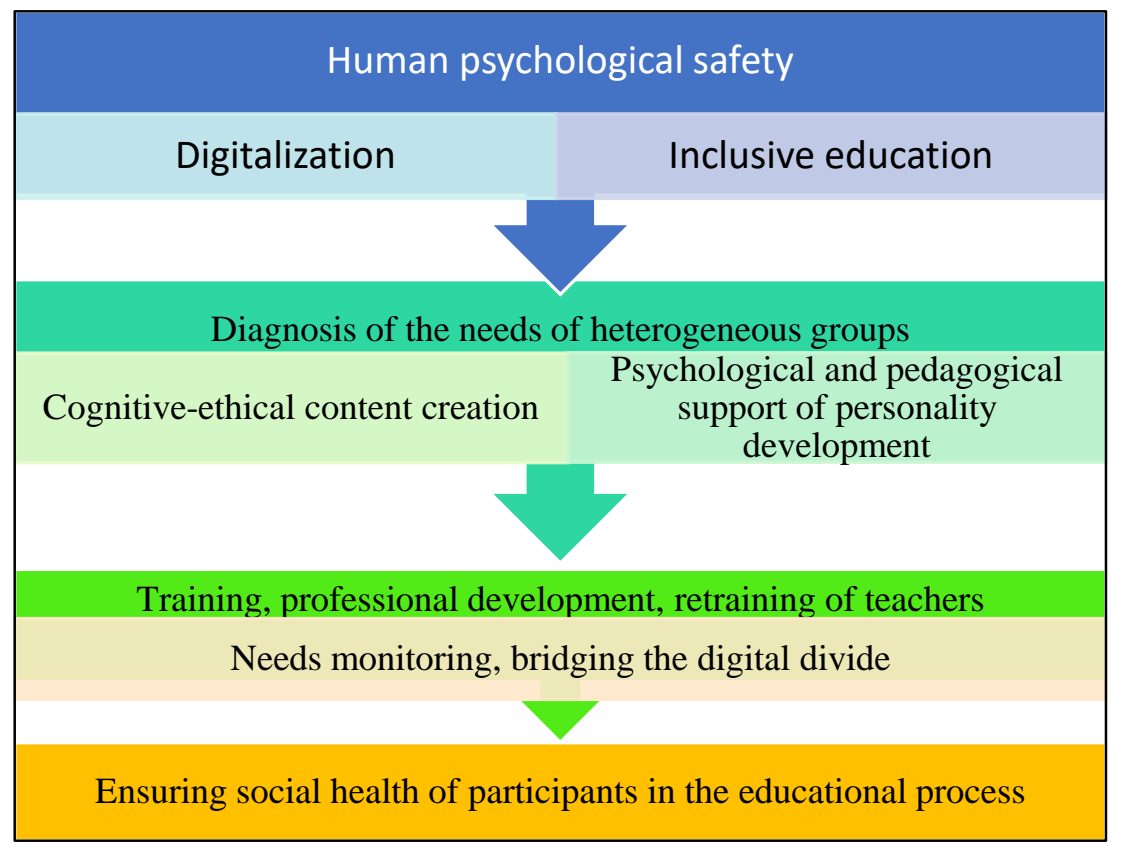

Fig. 1. Model of the structure of psychological safety of students in the context of digitalization as a factor of social health 
Mechanisms for implementing the model also developed the term in the intensive introduction of digital technologies in education (Fig. 2).

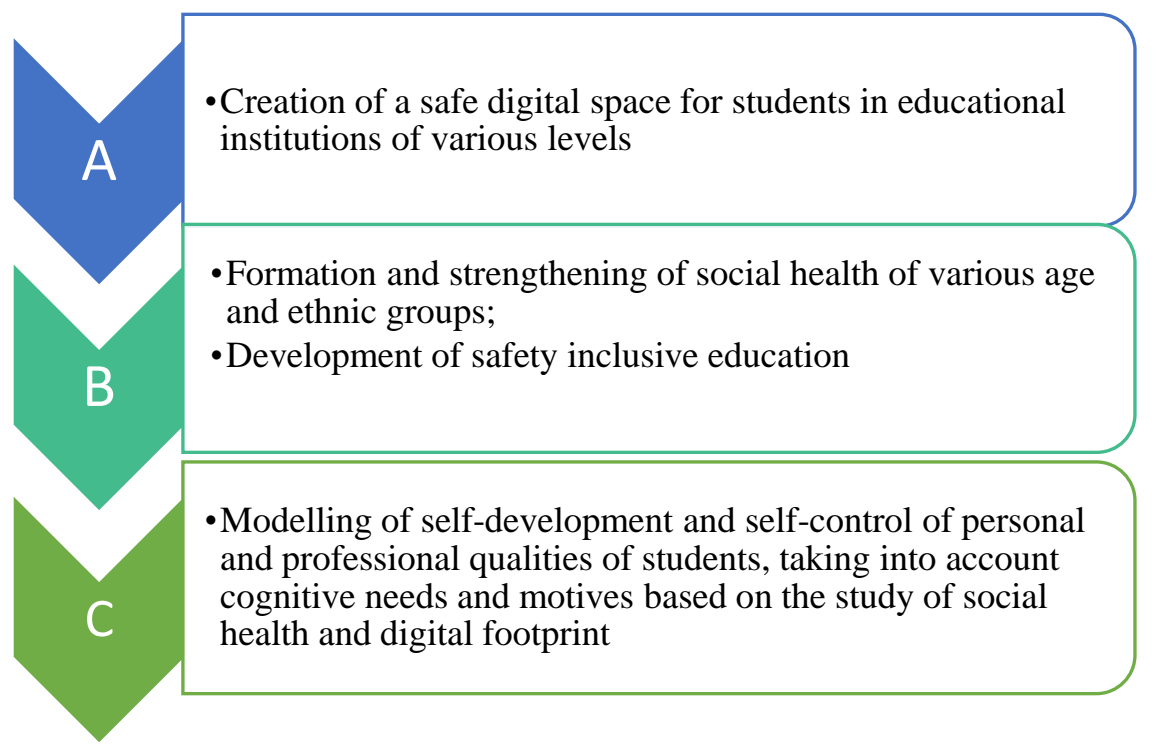

Fig.2. Mechanisms for implementing the model of the structure of psychological safety of students (in the context of digitalization as a factor of social health)

\section{Conclusion}

Modern developments in digital technologies and artificial intelligence indicate that the likelihood of the formation of a cyber-person has arisen. The importance of the professional development of a teacher in modern conditions of digitalization lies:

- in the advisable use of cyber technologies in teaching students

- in creating psychological safety for them in the modern digital educational environment. Society has accumulated considerable experience, which makes it possible to solve efficiently many complex issues arising in new trends in the evolution of education. Including resisting the emergence of a cyber-man, devoid of feelings, compassion, love, as the likelihood of disappearance of the teaching profession as a carrier of universal spirituality.

It also noted that education is becoming more and more inclusive. Social cognitive dissonance negatively affects the social health of educational participants. This paper presents a model of the concept of psychological safety of students, which includes such components as:

- safe digital content, taking into account age characteristics and ethnic and confessional values;

- preservation and strengthening of social health;

- self-development and self-control of personal and professional qualities of students, taking into account cognitive needs, motives and analysis of the digital footprint.

Due to its dynamic development in the period of globalization, modern education should be called inclusive. We consider the psychological safety of students in the context of the intensive implementation of digitalization in inclusive education as a factor in the social health of future labour resources. Our task is to realize the importance of technical achievements and their careful use in education, following the motto: "Not harm!" 


\section{References}

1. C.P. Alderfer, Existence, Relatedness, and Growth; Human Needs in Organizational Settings, (Free Press, 1972)

2. M. Baer, M. Frese, Journal of Organizational Behavior, 24(1), 4568 (2003)

3. T.V. Bashkireva, A.V. Bashkireva, V.A. Fulin, Some questions of psychological and pedagogical support of students to professional activities (Ryaz. State un-t them. S.A. Yesenin, 2020)

4. R. Benbunan-Fich, S.R. Hiltz, M. Turoff, Decision Support Systems, 34(4), 457 (2003)

5. H.G. Brown, M.S. Poole, T.L. Rodgers, Journal of Management Information Systems. 20 (4), 115137 (2004)

6. A. Carmeli, Long Range Planning, 40 (1), 3044 (2007)

7. C.C. Chen, R.S. Shaw, Journal of Distance Education Technologies, 4 (4), 88103 (2006)

8. C.-M. Chiu, M.-H. Hsu, S.-Y.Sun, T.-C. Lin, P.-C. Sun, Computers \& Education, 45 (4), 399416 (2005)

9. A.E. Colbert, M.K. Mount, J.K. Harter, L.A. Witt, M.R. Barrick, Journal of Applied Psychology, 89 (4), 599609 (2004)

10. A.C. Edmondson, Administrative Science Quarterly, 44(2), 350383 (1999)

11. A.C. Edmondson, Journal of Management Studies, 40 (6), 14191452 (2003)

12. A.C. Edmondson, Trust and distrust in organizations: Dilemmas and approaches, (Russell Sage Foundation, 2004)

13. A.C. Edmondson,R.M. Bohmer, G.P. Pisano, Administrative Science Quarterly, 46 (4), 685716 (2001)

14. G. Jones, J. George, The Academy of Management Review, 23 (3), 531546 (1998)

15. G. Slemp, J. Field, A. Cho, Journal of Vocational Behavior, 121 (2020)

16. V. Genia, Review of Religious, 38 (4), 344361 (1997)

17. K. William, The Academy of Management Journal, 33(4), 692724 (1990)

18. L. R. James, S. B. Sells, Psychological Climate: Theoretical Perspectives and Empirical Research Toward (Psychology Press, 1981)

19. L.L. Martins, F.W. Kellermanns, Academy of Management Learning \& Education, 3(1), 7 (2004)

20. A. Maslow, Toward a Psychology of Being, (Van Nostrand Reinhold, 1968)

21. D.R. May, R.L. Gilson, L.M. Harter, Journal of Occupational and Organizational Psychology,77,1137 (2004)

22. D.J. McAllister, Academy of Management Journal, 38 (1), 2459 (1995)

23. J.A. McCarty, L.J. Shrum, Public Opinion Quarterly, 64 (3), 271298 (2000)

24. A.V. Morozov, Herzen readings: psychological research in education, 1, 216223 (2018)

25. T. Mooij, Computers \& Education, 42 (1), 2544 (2004)

26. T. Mooij, E. Smeets, Computers \& Education, 36 (3), 265281 (2001)

27. K.J. Valadares, Health Care Manager, 23 (3), 220224 (2004)

28. E. M. van Raaij, J. Schepers, Computers \& Education, 50 (3), 838852 (20080 
29. P. Luksha, D. Peskov, Future education: a global agenda. CC BY RF Group www.refuture.me 2010-2013, http://www.eseur.ru/Files/file8711.pdf

30. M. del Karmen, O,Gomes, International Journal of Environmental Research and Public Health, 17, 5036 (2020)

31. J. Sweller, Implications of cognitive load theory for multimedia learning (Cambridge University Press, 2005)

32. H.C. Triandis, M.J. Gelfand,Journal of Personality and Social Psychology, 74 (1), 118128 (1998)

33. R. Wilkens, M. London, Journal of Vocational Behavior, 69 (3), 510523 (2006)

34. UNESCO, https://ru.unesco.org/ 